\section{References}

1. Michielon G, Di Carlo D, Brancaccio G, Guccione P, Mazzera E, Toscano A, et al. Anomalous coronary artery origin from the pulmonary artery: correlation between surgical timing and left ventricular function recovery. Ann Thorac Surg. 2003;76:581-8.

2. Batista RJV, Santos JLV, Takeshita N, Bocchino L, Lima PN, Cunha MA. Partial left ventriculectomy to improve left ventricular function in end-stage heart disease. J Card Surg. 1996;11:96-8.
3. Suma H, Isomura T, Horii T, Sato T, Kikuchi N, Iwahashi K, Hosokawa J. Nontransplant cardiac surgery for end-stage cardiomyopathy. J Thorac Cardiovasc Surg. 2000;119:1233-45.

4. Yoshii S, Hosaka S, Takahashi W, Amano H, Abraham SJK, Kaga S, et al. Partial left ventriculectomy in an infant with dilated cardiomyopathy. J Thorac Cardiovasc Surg. 1999;117:616-8.

5. Berger S, Tweddell JS, Frommelt PC, Weinhaus L. Partial left ventriculectomy for dilated cardiomyopathy in a newborn. J Thorac Cardiovasc Surg. 1999;117:1017-8.

\title{
Lung mass after pulmonary artery catheterization: Beware of the pulmonary artery false aneurysm
}

\author{
Cliff K. Choong, FRACS, and Bryan F. Meyers, MD, St Louis, Mo
}

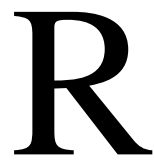

upture of the pulmonary artery (PA) or one of its branches during a right heart catheterization is a complication that is rare but remains fatal in almost $50 \%$ of cases. ${ }^{1}$ We report a case of PA false aneurysm caused by PA rupture, which presented as a lung mass 10 days after catheterization, that was correctly identified and successfully treated.

\section{Clinical Summary}

An 81-year-old woman with a history of atrial fibrillation presented with fatigue and decreased exercise tolerance and clinically was in congestive heart failure. Echocardiography revealed severe aortic stenosis and mild mitral regurgitation. She underwent cardiac catheterization for further evaluation, including PA catheterization. She had some hemoptysis immediately after the procedure, which resolved without further episode. Postprocedure chest radiography revealed no abnormality apart from changes consistent with congestive heart failure. Ten days later, a repeat chest radiograph revealed a rounded right lung mass (Figure 1, A). Chest computed tomography was performed to further investigate the lung mass, and this showed the mass to be in the right hilum of the lower lobe in contiguity with the right PA (Figure 1, B-D). A false aneurysm of the PA was suspected, and she underwent a right PA angiography, which confirmed it (Figure 2, $A$ and $B$ ). The aneurysm was successfully treated nonsurgically with coil embolization to occlude the inflow neck of the aneurysm (Figure 2, $C$ and $D$ ).

From the Division of Cardiothoracic Surgery, Department of Surgery, Washington University School of Medicine, St Louis, Mo.

Received for publication Jan 5, 2005; accepted for publication Jan 13, 2005

Address for reprints: Bryan F. Meyers, MD, Division of Cardiothoracic Surgery, Department of Surgery, Washington University School of Medicine, St Louis, MO 63119 (E-mail: meyersb@msnotes.wustl.edu).

J Thorac Cardiovasc Surg 2005;130:899-900

$0022-5223 / \$ 30.00$

Copyright $\odot 2005$ by The American Association for Thoracic Surgery

doi:10.1016/j.jtcvs.2005.01.019
Three days later, she underwent an aortic valve replacement with a bioprosthetic valve. Her intraoperative and

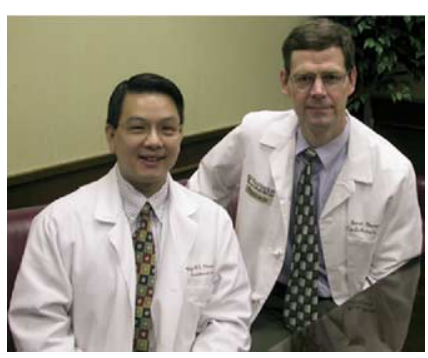

Choong and Meyers postoperative courses were uneventful and without evidence of recurrent PA hemorrhage. Before discharge, she was anticoagulated for her atrial fibrillation. At 2 years' follow-up, she had remained clinically well.

\section{Discussion}

Catheter-induced PA rupture is an infrequent but lethal complication occurring with an estimated frequency of $0.06 \%$ to $0.2 \%$. $^{1}$ Reported risk factors for catheter-induced PA rupture have included advanced age (age $>60$ years), catheter stiffness, prolonged balloon inflation, multiple manipulations of the catheter, peripheral placement of the catheter, pulmonary hypertension, and anticoagulation. ${ }^{1,2}$ Common modes of presentations have included hemoptysis with hypoxemia, exsanguination, delayed recurrent hemorrhage, and intraoperative pulmonary hemorrhage during or after cardiopulmonary bypass. ${ }^{3}$ False aneurysm of the PA is a rare presentation of PA rupture and should be considered as a possible diagnosis in a patient with a new lung mass after PA catheterization. ${ }^{4}$ Angiography is useful in the confirmation of the diagnosis and identification of the site of PA hemorrhage. ${ }^{5}$ Treatments have included control of the hemorrhage through conservative management, pulmonary resection, PA repair, and arterial embolization. Conservative management strategies have been associated with a high incidence of secondary and often fatal recurrent hemorrhage. ${ }^{1,3}$ Pulmonary resection is useful in controlling the bleeding but is associated with a high mortality and is reserved as a last resort. $^{3}$ Management by means of occlusion of the site of PA hemorrhage through embolization is the preferred initial treatment of choice and has the advantages of being quick, simple, and effective. ${ }^{5}$ Mortality from PA rupture, however, remains high, around $50 \%$, with uncontrolled hemorrhage leading to asphyxiation as the leading cause of death. ${ }^{1,3}$

In summary, we report of case of PA false aneurysm caused by catheter-induced PA rupture that presented as a new lung mass after PA catheterization. The diagnosis was confirmed by angiog- 

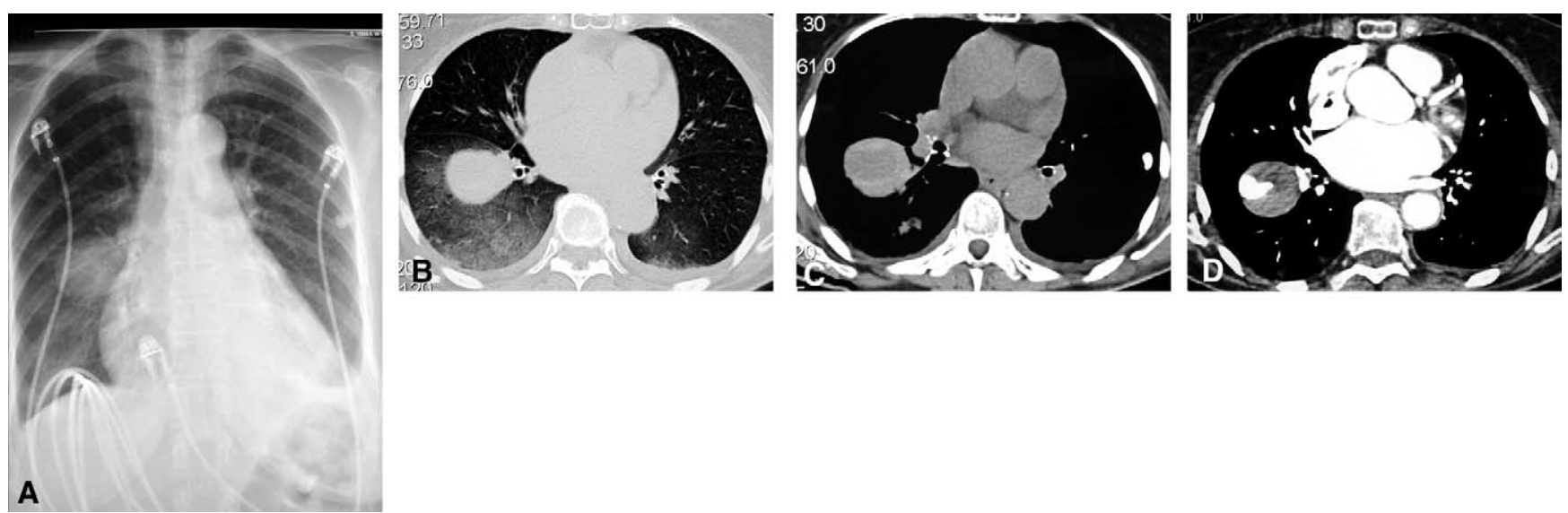

Figure 1. A, Chest radiograph showing a $4.5-\mathrm{cm}$ rounded opacity in the right lung field and moderate cardiomegaly. $B$ and C, Computed tomogram without intravenous contrast showing a smooth, contoured, $4.5-\mathrm{cm}$ lung mass in the superior segment of the right lower lobe. D, Computed tomogram with intravenous contrast showing the mass to be arising from the right lower lobe pulmonary artery.
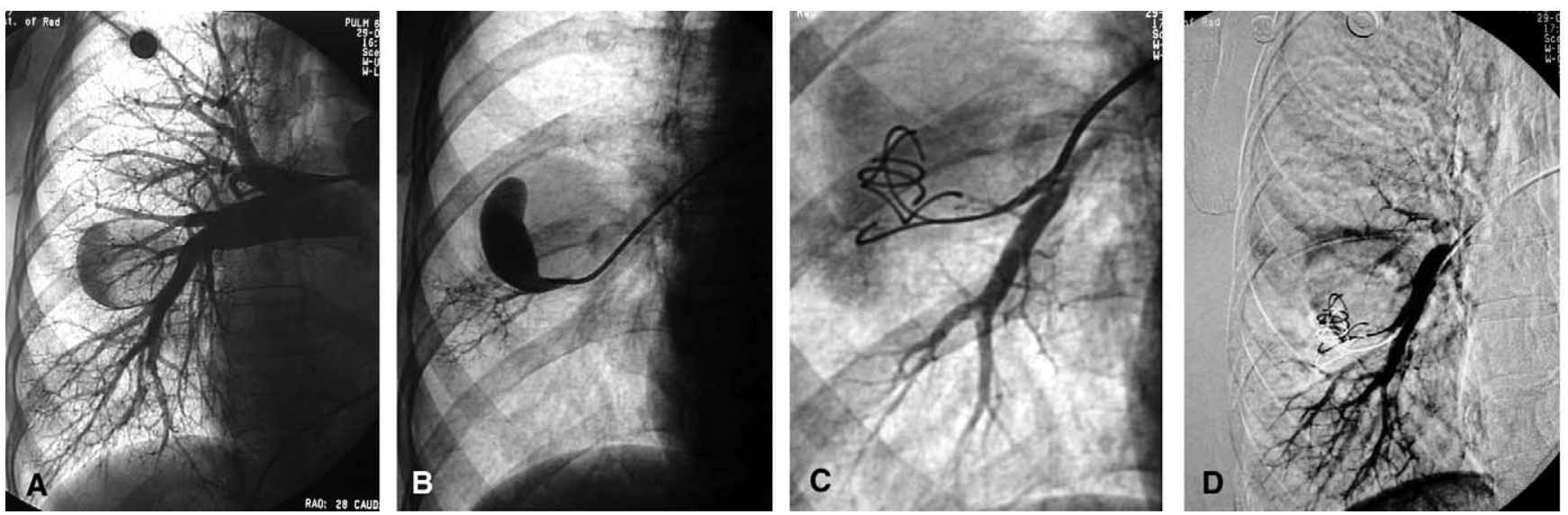

Figure 2. A, Right pulmonary angiogram demonstrating a large false aneurysm arising from a branch of the right lower lobe artery. B, Angiogram showing a crescentic false aneurysm arising from a small neck. C, Angiogram showing deployment of coils. D, Follow-up selective angiogram demonstrating no filling of the false aneurysm after embolization.

raphy, and it was successfully treated with coil embolization allowing the patient to undergo an uneventful aortic valve replacement 3 days later.

\section{References}

1. Sirivella S, Gielchinsky I, Parsonnet V. Management of catheterinduced pulmonary artery perforation: a rare complication in cardiovascular operations. Ann Thorac Surg. 2001;72:2056-9.
2. Barash PG, Nardi D, Hammond G, et al. Catheter induced PA perforation. Mechanisms, management and modifications. J Thorac Cardiovasc Surg. 1981;82:5-12.

3. Urschel JD, Myerowitz D. Catheter-induced pulmonary artery rupture in the setting of cardiopulmonary bypass. Ann Thorac Surg. 1993;56: 585-9.

4. Ferretti GR, Thony F, Link KM, et al. False aneurysm of the pulmonary artery induced by a Swan-Ganz catheter: clinical presentation and radiologic management. AJR Am J Roentgenol. 1996;167:941-5.

5. Gottwalles Y, Wunschel-Joseph M, Hanssen M. Coil embolization treatment in pulmonary artery branch rupture during Swan-Ganz catheterization. Cardiovasc Intervent Radiol. 2000;23:477-9. 